Research Article

\title{
Design of Independent Type-B LNG Fuel Tank: Comparative Study between Finite Element Analysis and International Guidance
}

\author{
Tae-Wook Kim ${ }^{(D)},{ }^{1}$ Seul-Kee Kim, ${ }^{1}$ Seong-Bo Park, ${ }^{2}$ and Jae-Myung Lee ${ }^{1}{ }^{1}$ \\ ${ }^{1}$ Department of Naval Architecture and Ocean Engineering, Pusan National University, \\ Busandaehak-ro 63 beon-gil 2, 46241 Busan, Republic of Korea \\ ${ }^{2}$ Maritime Research Institute, Hyundai Heavy Industries Co., Ltd., Bangeojinsunhwan-doro 1000, \\ 44032 Ulsan, Republic of Korea \\ Correspondence should be addressed to Jae-Myung Lee; jaemlee@pusan.ac.kr
}

Received 9 February 2018; Accepted 19 March 2018; Published 8 April 2018

Academic Editor: Luigi Nicolais

Copyright (C) 2018 Tae-Wook Kim et al. This is an open access article distributed under the Creative Commons Attribution License, which permits unrestricted use, distribution, and reproduction in any medium, provided the original work is properly cited.

In 2012, the International Maritime Organization (IMO) regulated the emissions of $\mathrm{SO}_{x}$ and $\mathrm{NO}_{x}$ by setting the emission control area and strengthened the regulations on ship building and operation. Because the environmental regulations have been reinforced, there has been a drastic increase in LNG-fueled ships. Therefore, it is necessary to carry out systematic research on the design of the LNG fuel tank, which is one of the important components of LNG fuel supply systems. In this study, aiming to design a type-B LNG fuel tank used in the real structure, a procedure for structural integrity assessment considering the International Gas Carrier (IGC) Code was proposed. A 10,000 TEU containership was chosen as an operating vessel, and independent type-B tank was selected as an LNG fuel tank. Structural integrity was evaluated by applying a systematic procedure based on the IGC Code. A series of finite element analysis was conducted under the various design loads and operating conditions. Fatigue life and fatigue damage were calculated using the numerical results obtained from transient thermal-structural analysis and fatigue analysis to provide the safety level of the design scheme.

\section{Introduction}

In 2012, the International Maritime Organization (IMO) regulated the emissions of $\mathrm{SO}_{x}$ and $\mathrm{NO}_{x}$ in ships and offshore fields by setting the emission control area. In this regulation, the sulfur contents $\left(\mathrm{SO}_{x}\right)$ should be limited to $0.1 \%$ weight from 2015 onward in sulfur emission control areas (SECAs) [1]. In addition, with the aim of reducing greenhouse gas emissions by $20 \%$ in 2020 and by $50 \%$ in 2050 from their 2005 level, IMO strengthened the regulations on ship building and operation to satisfy the energy efficiency design index (EEDI) criteria agreed upon by IMO at MEPC 62 [2]. The $\mathrm{SO}_{x}$ reduction problem can be solved and the EEDI index associated with $\mathrm{CO}_{2}$ can be reduced by $20 \%$ by applying an LNG fuel supply system to ships [3]. Because these environmental regulations have been reinforced, the demand for liquefied natural gas- (LNG-) fueled ships is expected to dramatically increase. In this context, it is necessary to carry out research on the design of the LNG fuel tank, which is one of the important components of the LNG fuel supply system.

Fuel tanks applied to LNG-fueled ships are categorized into IMO-independent type- $\mathrm{A}$, type- $\mathrm{B}$, and type- $\mathrm{C}$ tanks. A comparison of these tanks is shown in Table 1 [4]. Type-A tank is designed as an independent prismatic type and has a complete secondary barrier for the entire tank. Type-B tank is similar to type-A except that it has a partial secondary barrier for a fail-safe design. The prismatic shape tank has a supporting system and a secondary barrier covering the entire inner bottom plate. This type is resistant to sloshing loads, as the tank has longitudinal bulkheads. By contrast, the type-C tank is a cylindrical tank for small vessels of capacities below $20,000 \mathrm{~m}^{3}$.

At present, despite the numerous studies on LNG cargo tanks, very few analyzed the fuel tank design. Basically, heat 
TABLe 1: Comparison of independent type tanks for LNG-fueled ships.

Tank type
IMO tank type
$\begin{aligned} & \text { Schematic } \\ & \text { structure } \\ & \text { barrier } \\ & \text { Characteristic }\end{aligned}$
$\begin{aligned} & \text { Pressurized at ambient or } \\ & \text { lower temperature } \\ & \text { For small vessels less than } \\ & \text { approx. 20,000 } \mathrm{m}^{3} \text { capacity }\end{aligned}$

transfer analysis, thermal analysis, and a comparative study on thermal insulation of LNG cargo tanks were conducted [5-7]. Furthermore, studies on structural integrity assessment and design of type-C LNG tanks applied for LNG carriers of various sizes were performed $[8,9]$, and a structural design of an LNG cargo tank for LNG carriers was conducted [10]. In addition, a load analysis of an independent type cargo tank for LNG carriers and numerical simulation of liquid sloshing in ship tanks were also carried out $[11,12]$, as well as a timedomain stress analysis for the rolling chock of an independent type LNG tank [13]. Finally, a fatigue analysis method for an LNG tank was presented, and a fatigue strength assessment for an LNG cargo tank was conducted $[14,15]$.

Although numerous studies were conducted for the optimum design and structural integrity assessment of the membrane type or type- $\mathrm{C}$ tank, analytical studies on type-B LNG fuel tanks according to codes are inadequate and difficult to find. This is due to the difficulty of finding a wellestablished procedure for the structural integrity assessment of type-B LNG fuel tanks. Therefore, in this study, to design the type-B LNG fuel tank that is used in the real structure, a procedure for structural integrity assessment considering the International Gas Carrier (IGC) Code was proposed. Accordingly, a structural integrity assessment of the tank was conducted based on finite element analysis (FEA). The results were verified according to the IGC Code and several other rules.

\section{Structural Integrity Assessment Procedure for LNG Fuel Tanks}

2.1. Overall Assessment Procedure for LNG Fuel Tanks. In the present study, to design the type-B LNG fuel tank, a procedure for structural integrity assessment according to the IGC Code for optimum design was proposed. The procedure includes the thermal-structural analysis and fatigue analysis and is based on the IGC Code, KR Rules, IACS Recom. 56, DNV Class Note No. 31.12, and ASME Sec. VIII, Div. 2. The proposed assessment procedure for the safety and reliability of the LNG fuel tank considering the IGC Code is summarized in Figure 1.
The structural integrity assessment was carried out by applying the proposed procedure. The most important factors involved in the design of the LNG fuel tank are structural safety and fatigue life, as LNG is stored at a temperature below $-163^{\circ} \mathrm{C}$. Finally, a systematic FEA was performed to evaluate the structural safety and to establish a procedure for analyzing the stress levels and evaluating the fatigue life of the target structure. In particular, the thermal-structural analysis and fatigue analysis were carried out using the databases on the materials and structures of LNG fuel tanks.

2.1.1. Heat Transfer Analysis. As a first step in the structural integrity assessment, a heat transfer analysis was conducted. LNG is stored in the liquid state at $-163^{\circ} \mathrm{C}$ to minimize volume and large differences in temperatures between the inner and outer tanks. Therefore, thermal effects should be reflected in FEA when evaluating the structural safety of the LNG fuel tank [16]. Heat transfer analysis due to natural convection of LNG according to the filling ratio was performed to obtain the exact temperature distribution in the LNG fuel tank. Three filling ratios were selected to reflect the change of the inner LNG mass in operation: $15 \%, 50 \%$, and 90\% (Figure 2) [17]. As a result, each stress due to thermal shrinkage was obtained from the heat transfer analysis by applying the acquired temperature distribution.

2.1.2. Structural Analysis. As a second step in the structural integrity assessment of the LNG fuel tank, the structural analysis was conducted according to the IGC Code to evaluate the structural safety of the tank. The scope of the structural evaluation was limited to the design of the LNG fuel tank and support structures. Since the material is in a cryogenic environment, it is essential to consider nonlinearity [18]. Accordingly, a nonlinear analysis wasperformed by applying the stress-strain relation obtained from the actual ambient and cryogenic test of the stainless steel material in contact with the LNG [19]. In the analysis, the stress-strain relation was applied to each part according to the temperature distribution obtained from the heat transfer analysis (Figure 3). The charging and consuming 


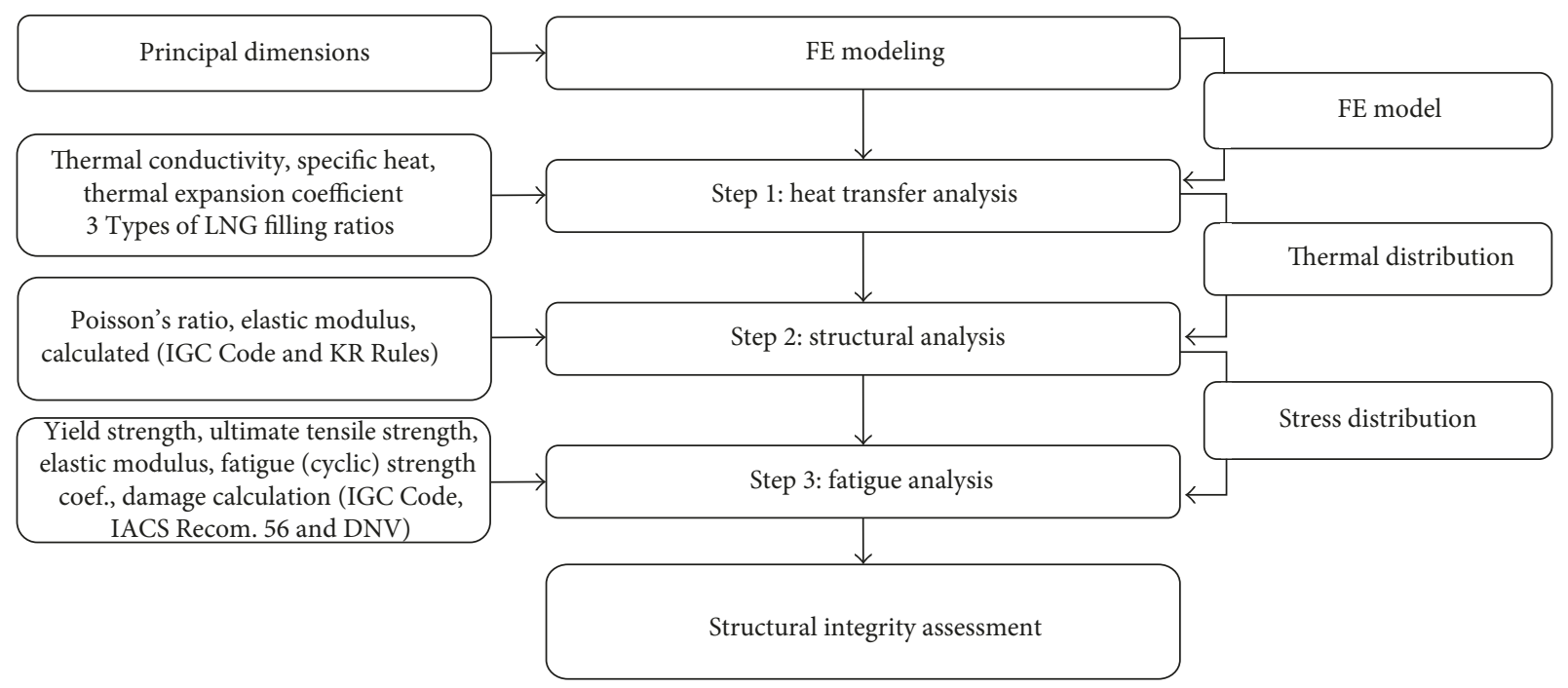

FIGURE 1: Flowchart of proposed structural integrity assessment of the LNG fuel tank.

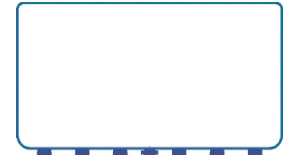

(a)

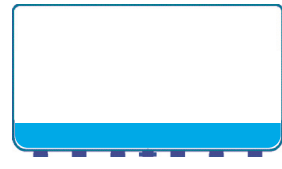

(b)

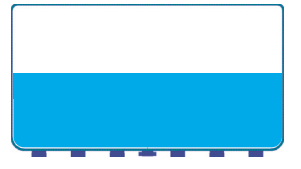

(c)

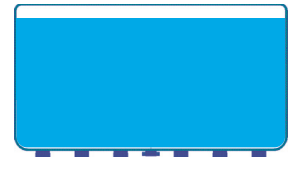

(d)

FIGURE 2: Loading conditions for considering different filling ratios of the LNG fuel tank: (a) empty state, (b) $15 \%$, (c) $50 \%$, and (d) $90 \%$.

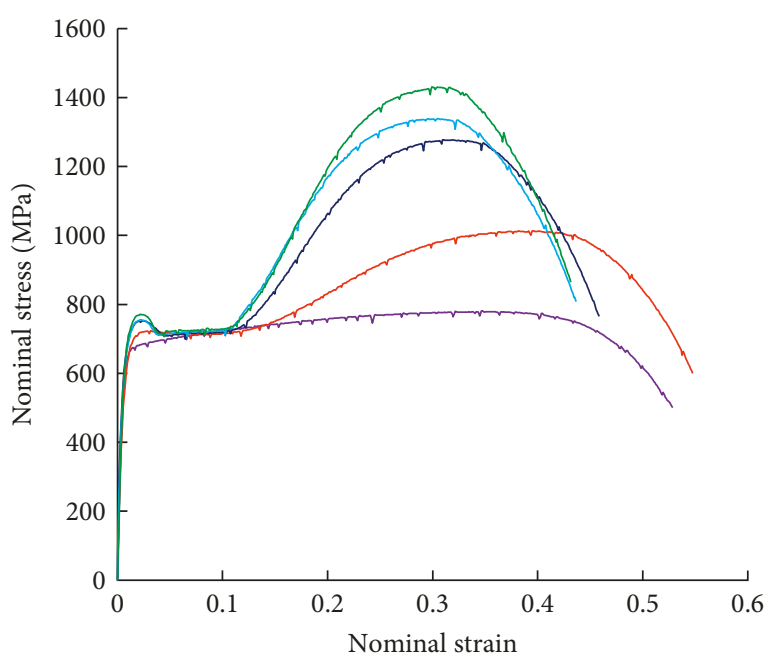

$$
\begin{array}{ll}
\text { Strain rate } 10^{-4} \mathrm{~s}^{-1} & \\
-20^{\circ} \mathrm{C} & -140^{\circ} \mathrm{C} \\
--50^{\circ} \mathrm{C} & -163^{\circ} \mathrm{C} \\
- & -120^{\circ} \mathrm{C}
\end{array}
$$

FIGURE 3: Temperature-dependent stress-strain relation of stainless steel.

processes of LNG and the changes in temperature inside and outside of the tank were not considered. The FEA was performed considering the internal pressure, hydrostatic pressure according to the LNG filling ratio, and thermal load from the heat transfer analysis. The tank for transporting
LNG was considered for dynamic effects because loading and unloading conditions are repetitive. However, because the fuel in the tank is consumed gradually during the voyage, the static analysis was performed.

2.1.3. Fatigue Analysis. As a third step, fatigue analysis was performed. Because the fuel tank is exposed to more frequent severe fatigue loads, such as cyclic impact loading of LNG and thermal loading under cryogenic conditions, a study on the fatigue fracture and fatigue life of the LNG fuel tank should be undertaken. Therefore, the standard related to fatigue analysis of LNG fuel tanks was applied. Accordingly, a fatigue analysis for the entire structure of the LNG fuel tank was conducted in this study. This analysis was performed using the structural analysis results. The analysis was conducted according to the IGC Code, IACS Recom. 56, and ASME Sec. VIII, Div. 2. The fatigue life of the fuel tank structure was assessed using global FEA. In addition, a fatigue tool inside the FEA programs, MSC.Patran/Nastran 2010, was used [20-22].

2.2. Conceptual Design of Type-B LNG Fuel Tank. Among the various LNG tank types, independent type-B tank is the most suitable in terms of compliance to recent trends of environmental regulations and it is highly reliable. It has sufficient fatigue strength to prevent crack penetration during its design life. It is a category of tanks that complies with the safety requirements of the IGC Code. The safety of the LNG fuel tank can be ensured by selecting the 


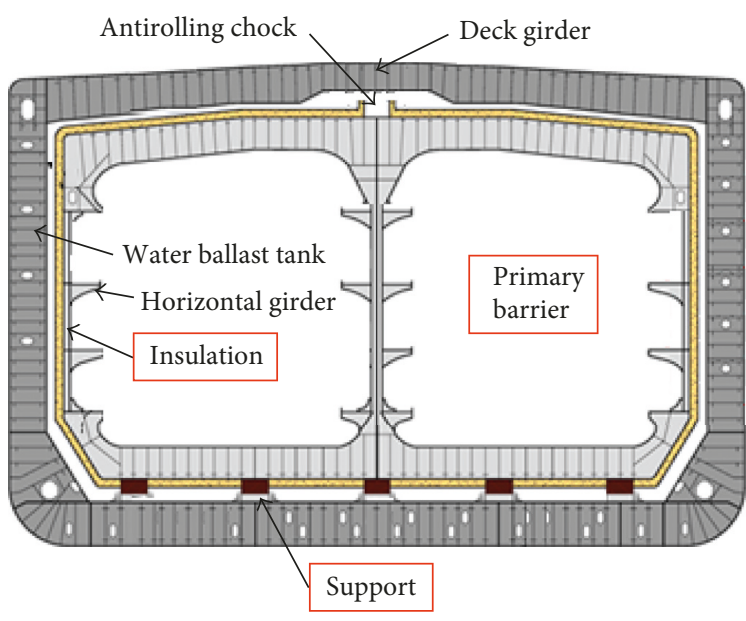

(a)

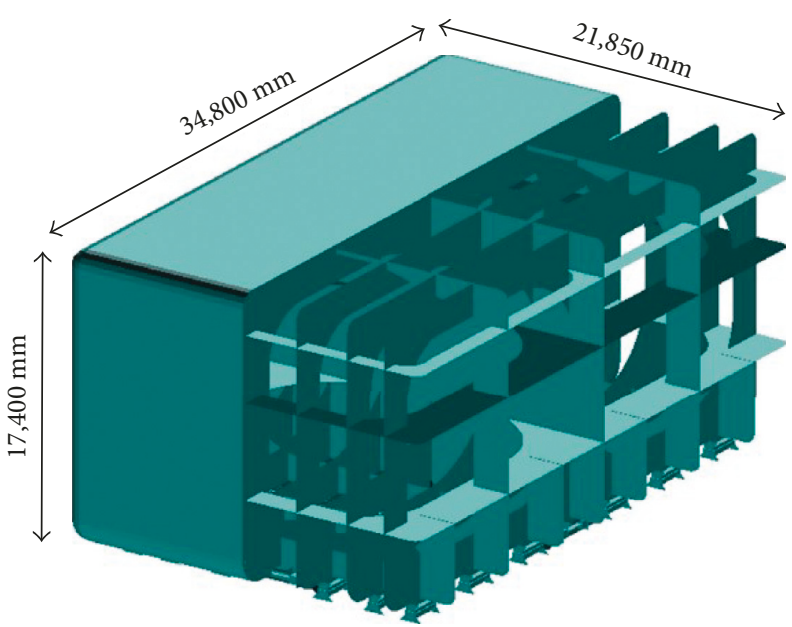

(b)

Figure 4: Schematic presentation of the structural design and size of a type-B independent tank.

appropriate structural material, as well as by optimizing its structural design. Figure 4 shows the schematic of the structural design concept of the type-B independent tank. The dimensions of the target structure are $21.85 \mathrm{~m}$ (length) $\times$ $34.8 \mathrm{~m}$ (breadth) $\times 17.4 \mathrm{~m}$ (height). As shown in Figure 4 , the LNG fuel tank consists of the following three different parts:

(1) A primary barrier: It has direct contact with LNG and is made of AISI 304L stainless steel, which absorbs the thermal deformation caused by the cryogenic temperature.

(2) An insulation panel surrounding the primary barrier: It is composed of polyurethane foam (PUF), which is typically used as an insulation material for independent-type LNG fuel tanks.

(3) A support structure: It is the middle part, which is composed of compressed wood and functions as support. The properties of each material constituting the tank are summarized in Table 2 .

2.3. Finite Element Model. The finite element (FE) model for the type-B LNG fuel tank was based on the tank drawing data. The MSC.Patran was used as the preprocessor for FE modeling, and MSC.Nastran was used as the solver for FE analysis. The type-B LNG fuel tank is designed as a prismatic and is geometrically symmetrical in the longitudinal direction; thus, only half of the tank was used for the FE model.

For the SUS304L material, the mesh work was performed by using a quadrilateral shell element with four nodes. By contrast, the mesh work for wood and PUF was performed by using hexahedral solid elements with eight nodes. The element size of the primary barrier is $250 \mathrm{~mm} \times 250 \mathrm{~mm}$, and the element size of the support part is a quarter of that of the primary barrier. The fine mesh work was performed to share the node of elements of different sizes (Figure 5). Thus, the number of elements is 343,108 .

The mesh convergence was based on a mesh study performed for an LNG fuel tank model similar to the one used in
TABLE 2: Mechanical and thermal properties of materials of tank components.

\begin{tabular}{|c|c|c|c|}
\hline & SUS304L & PUF & Wood \\
\hline Poisson's ratio & 0.3 & 0.4 & 0.024 \\
\hline Elastic modulus ( $\mathrm{MPa})$ & $193 \times 10^{3}$ & 191 & 10,600 \\
\hline Density (tonnage $/ \mathrm{mm}^{3}$ ) & $8 \times 10^{-9}$ & $3 \times 10^{-11}$ & $1.2 \times 10^{-10}$ \\
\hline Yield stress $(\mathrm{MPa})$ & $\begin{array}{c}340.6\left(20^{\circ} \mathrm{C}\right) \\
556.3\left(-163^{\circ} \mathrm{C}\right)\end{array}$ & 2.7 & 63 \\
\hline $\begin{array}{l}\text { Thermal conductivity } \\
\left(\mathrm{W} / \mathrm{m}^{2}{ }^{\circ} \mathrm{C}\right)\end{array}$ & 14 & $2.5 \times 10^{-2}$ & $4 \times 10^{-2}$ \\
\hline $\begin{array}{l}\text { Specific heat } \\
\left(\mathrm{J} / \text { tonnage }{ }^{\circ} \mathrm{C}\right)\end{array}$ & $5 \times 10^{5}$ & $1.5 \times 10^{6}$ & $1.6 \times 10^{-6}$ \\
\hline $\begin{array}{l}\text { Thermal expansion } \\
\text { coefficient }\left(\mathrm{mm} / \mathrm{mm}^{\circ} \mathrm{C}\right)\end{array}$ & $1.7 \times 10^{-5}$ & $8 \times 10^{-5}$ & $6.1 \times 10^{-6}$ \\
\hline
\end{tabular}

the present study [23], and the required mesh size in fine mesh areas did not exceed $15 t \times 15 t$, where $t$ is the main plate thickness [24]. The analysis was carried out through this fine mesh work, and the validity was verified. Furthermore, boundary conditions between the support and the second barrier and between the antirolling and pitching device and the second barrier were applied using a fixed condition for the $x$-axis and $y$-axis and a free-end condition for the $z$-axis. In addition, to consider the contact in the support and antirolling and pitching device, a contact condition was given by applying a coefficient of friction considering sliding between the wood block and steel caused by thermal shrinkage and expansion.

As a result, we could investigate the characteristics of the stress occurring in the tank by the pressure applied. Moreover, by minimizing the number of elements of the model, the accuracy of the simulation was enhanced and the time to perform the thermal-structural analysis and fatigue analysis was reduced.

\section{Heat Transfer Analysis}

3.1. Initial Condition and Variable Determination. In this study, the heat transfer process in an LNG tank at various 


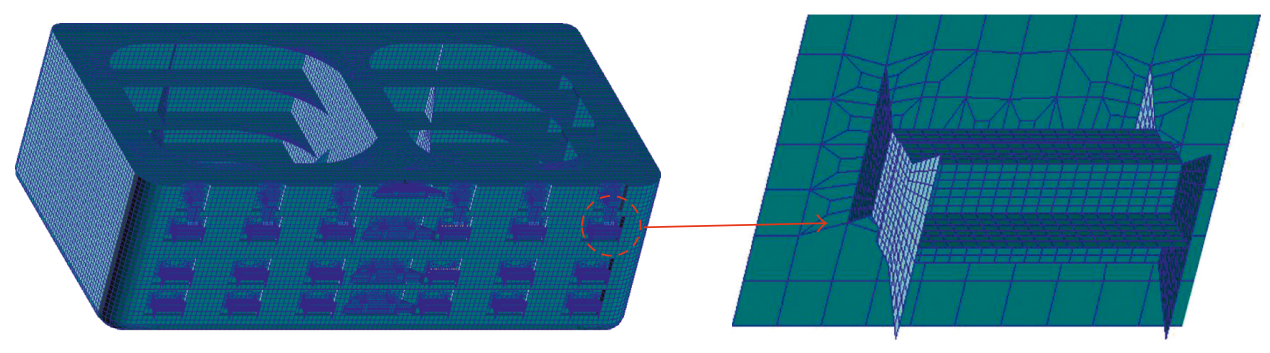

FIGURE 5: Fine mesh generation of the tank support structure.

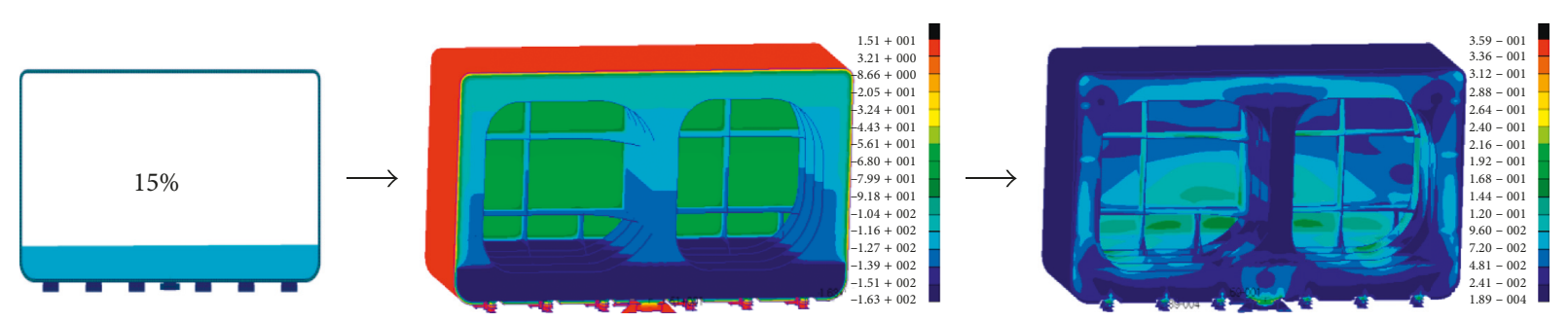

(a)
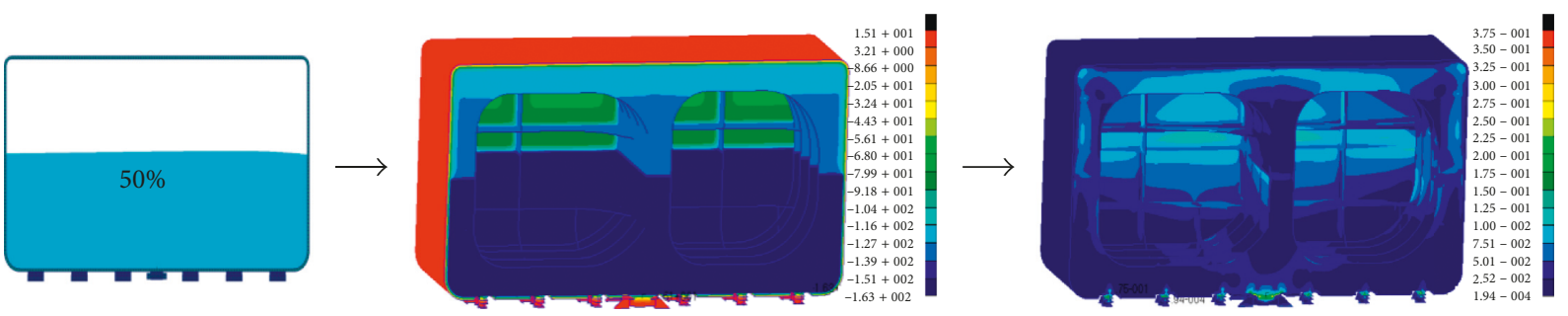

(b)
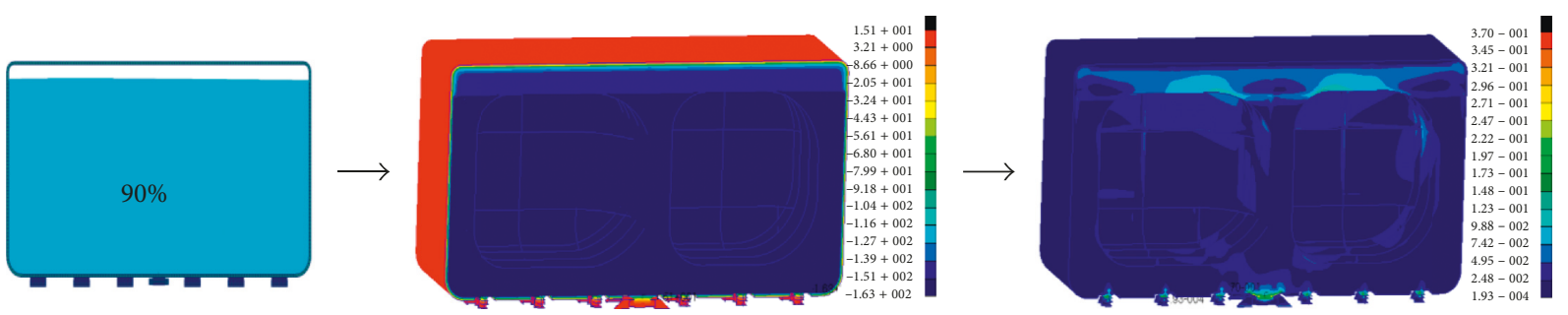

(c)

Figure 6: Temperature distribution and thermal stress distribution of the LNG fuel tank with (a) 15\%, (b) 50\%, and (c) $90 \%$ filling ratios.

filling ratios was analyzed using the finite element method [25-27]. The analysis was carried out assuming the threedimensional unsteady state with no heat generation in a fixed region of space [28]. The convection condition was applied with a convection coefficient and bulk temperature in the inner and outer surfaces of the tank, together with the element properties (Table 2). Only convection was expected to occur within the tank containing LNG and air. In this work, the LNG convection coefficient was set at $3000 \mathrm{~W} / \mathrm{m}^{2}{ }^{\circ} \mathrm{C}$ and that of the air was $20 \mathrm{~W} / \mathrm{m}^{2}{ }^{\circ} \mathrm{C}$. The temperature of the $\mathrm{LNG}$ was set as $-163^{\circ} \mathrm{C}$. In addition, the heat transfer characteristics of the outer region of the tank were ignored, and the boundary temperature conditions were assumed to be constant. If LNG is loaded into a fuel tank without cooling, significant shrinkage would occur rapidly, leading to problems such as cracking of the tank shell [29]. For this reason, the inner tank temperature was reduced to $-130^{\circ} \mathrm{C}$ before loading the LNG into the fuel tank. Thus, the initial inner temperature of the LNG fuel tank was set at $-130^{\circ} \mathrm{C}$, and the initial outer temperature was set as $15^{\circ} \mathrm{C}$.

3.2. Heat Transfer Analysis Results. Heat transfer analysis according to filling ratios was performed. Analysis conditions on thermal load of the LNG fuel tank with 15, 50, and $90 \%$ filling ratios were employed. As a result, the temperature distribution and thermal stress distribution of the LNG fuel tank for all filling ratios were obtained (Figure 6). For all filling ratio levels, the maximum stress level is observed at the support. It is known that maximum stresses occurred at parts where large shrinkage is expected. Consequently, it is considered that the influence on the filling ratio in the thermal analysis need not be deliberated 


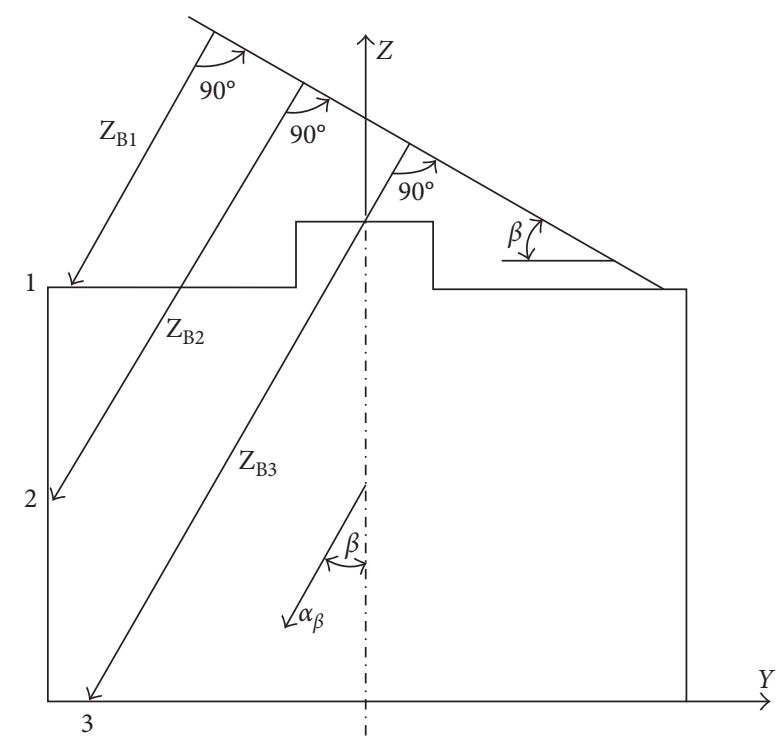

Figure 7: Determination of liquid height, $Z_{\beta}$ [30].

because no large differences owing to the filling ratios are observed.

\section{Structural Analysis}

4.1. Design Load Calculation and Simulation Method. In this study, the loading conditions applied to the structural analysis were combined with thermal load, vapor pressure, and internal liquid pressure assuming that the effect of heeling is very small. The equations for pressures except the thermal load were obtained from the IGC Code 1993 edition [30]. Accordingly, each pressure was derived for application to the structural analysis according to the rule.

4.1.1. Thermal Load and Vapor Pressure Estimation. In the previous section, to derive the thermal load, the temperature distribution was obtained by performing an analysis where the amount of LNG in the tank was first considered. Subsequently, the thermal load was derived from the temperature distribution with $90 \%$ filling ratio and then applied to the structural analysis. Considering that these tanks are primarily constructed with plane surfaces (prismatic tanks), the design vapor pressure $\left(P_{0}\right)$ should be less than $0.07 \mathrm{MPa}$. Therefore, the design vapor pressure for the fuel tank was set as $0.07 \mathrm{MPa}$.

4.1.2. Liquid Pressure Calculation. Finally, the internal liquid pressures $\left(P_{\mathrm{gd}}\right)$ are those arising from the resulting acceleration of the cargo's center of gravity due to ship motions. The value of $P_{\mathrm{gd}}$ resulting from the combined effects of gravity and dynamic accelerations should be calculated as follows:

$$
P_{\text {gd }}=\alpha_{\beta} Z_{\beta} \frac{\rho}{1.02 \times 10^{5}}(\mathrm{MPa}),
$$

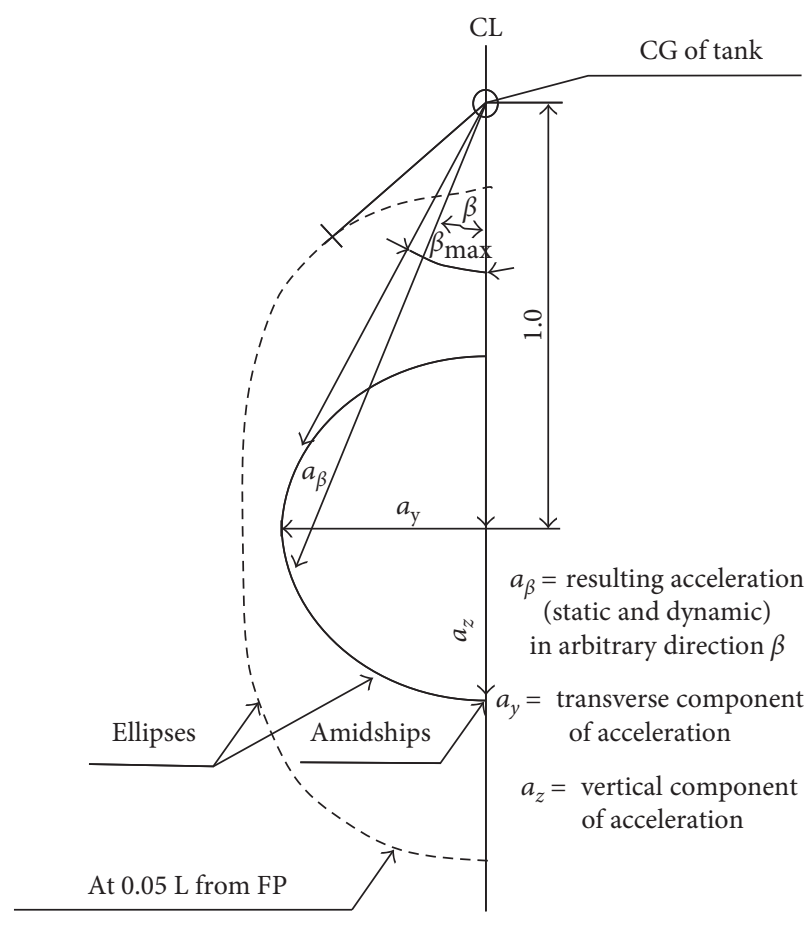

Figure 8: Acceleration ellipsoid [30].

where $\alpha_{\beta}$ is the dimensionless acceleration resulting from gravitational and dynamic loads in an arbitrary direction $\beta$ (Figure 7 ); $Z_{\beta}$ is the largest liquid height (m) above the point where the pressure is to be determined, measured from the tank shell in the $\beta$ direction (Figure 8); and $\rho$ is the maximum cargo density $\left(\mathrm{kg} / \mathrm{m}^{3}\right)$ at the design temperature. In this regard, the guidance for the calculation of the associated dynamic liquid pressure for the purpose of static design calculations was provided. This pressure may be used to determine the internal pressure. $\left(P_{\mathrm{gd}}\right) \max$ is the associated liquid pressure determined using the maximum design accelerations. $\left(P_{\mathrm{gd}}\right.$ site) $\max$ is the associated liquid pressure determined using site-specific accelerations. $P_{\text {eq }}$ should be the greatest of $P_{\text {eq } 1}$ and $P_{\text {eq2 }}$ calculated as follows:

$$
\begin{aligned}
& P_{\text {eq } 1}=P_{0}+\left(P_{\mathrm{gd}}\right) \max , \\
& P_{\text {eq } 2}=P_{h}+\left(P_{\mathrm{gd}} \text { site }\right) \max (\mathrm{MPa}) .
\end{aligned}
$$

The calculation of $\alpha_{\beta}$ and $Z_{\beta}$ to determine $P_{\text {gd }}$ proceeds as follows. For the acceleration ellipse in the $x-z$ plane of Figure 8 , the value of $\alpha_{\beta}$ in any arbitrary direction can be described using the equation of an ellipse as follows:

$$
\frac{a_{\beta x}^{2}}{a_{x}^{2}}+\frac{a_{\beta z}^{2}}{a_{z}^{2}}=1 .
$$

By making $a_{\beta x}$ the subject of the formula (3) and setting $a_{\beta z}=a_{\beta x} \tan ((\pi / 2)-\beta)-1$, the following equation is obtained: 


$$
a_{\beta x}=\frac{\tan ((\pi / 2)-\beta) a_{x}^{2} \pm \sqrt{(\tan ((\pi / 2)-\beta))^{2} a_{x}^{4}-a_{x}^{2}\left(\left(a_{z}^{2}+(\tan ((\pi / 2)-\beta))^{2} a_{x}^{2}\right)\left(1-a_{z}^{2}\right)\right)}}{a_{z}^{2}+(\tan ((\pi / 2)-\beta))^{2} a_{x}^{2}} .
$$

Thus, $a_{\beta x}$ is described as a function of $\beta, \alpha_{x}$, and $\alpha_{z}$ as follows:

$$
a_{\beta x}=\sqrt{1+(\tan ((\pi / 2)-\beta))^{2}} \frac{\tan ((\pi / 2)-\beta) a_{x}^{2} \pm \sqrt{(\tan ((\pi / 2)-\beta))^{2} a_{x}^{4}-a_{x}^{2}\left(\left(a_{z}^{2}+(\tan ((\pi / 2)-\beta))^{2} a_{x}^{2}\right)\left(1-a_{z}^{2}\right)\right)}}{a_{z}^{2}+(\tan ((\pi / 2)-\beta))^{2} a_{x}^{2}} .
$$

$\beta_{\max }$ and $Z_{\beta}$ are obtained by solving the above equations and $\left(P_{\mathrm{gd}}\right)$ max, determined using (1):

$$
\begin{aligned}
& \beta_{\max }=\frac{\pi}{2}-\tan ^{-1} \frac{1-a_{z}^{2}}{a_{x} \sqrt{1-a_{z}^{2}}}, \\
& Z_{\beta}=(H+B \tan \beta) \cos \beta .
\end{aligned}
$$

4.1.3. Dynamic Acceleration Calculation. The accelerations defined in (7) that are used to determine the internal liquid pressure were calculated using the geometrical data. Equation (8) below is given as guidance for the components of acceleration due to ship motions corresponding to a probability level of $10^{-8}$ and applied to ships with lengths exceeding $50 \mathrm{~m}$ and at or near their service speed. The geometrical data of the target ship in the structural analysis are listed in Table 3, and the calculated results of the accelerations are listed in Table 4.

$$
\begin{aligned}
& \text { Vertical acceleration: } a_{z}= \pm a_{0} \sqrt{1+\left(5.3-\frac{45}{L_{0}}\right)^{2} \cdot\left(\frac{x}{L_{0}}+0.05\right)^{2} \cdot\left(\frac{0.6}{C_{\mathrm{B}}}\right)^{1.5}+\left(\frac{0.6 y K^{1.5}}{B}\right)^{2}}, \\
& \text { transverse acceleration: } a_{y}= \pm a_{0} \sqrt{0.6+2.5\left(\frac{x}{L_{0}}+0.05\right)^{2}+K\left(1+0.6 K \frac{z}{B}\right)^{2}},
\end{aligned}
$$

longitudinal acceleration: $a_{x}= \pm a_{0} \sqrt{0.06+A^{2}-0.25 A}$.

$$
a_{0}=0.2 \frac{V}{\sqrt{L_{0}}}+\frac{34-\left(600 / L_{0}\right)}{L_{0}},
$$

where $L_{0}$ is the length of the ship for determination of scantlings, as defined in recognized standards $(m) ; C_{B}$ is the block coefficient; $B$ is the largest molded breadth of the ship $(\mathrm{m}) ; x$ is the longitudinal distance $(\mathrm{m})$ from amidships to the center of gravity of the tank with contents, where $x$ is positive forward of amidships and negative aft of amidships; $y$ is the transverse distance $(\mathrm{m})$ from the centerline to the center of gravity of the tank with contents; moreover, $z$ is the vertical distance $(\mathrm{m})$ from the ship's actual waterline to the center of gravity of the tank with contents, where $z$ is positive above and negative below the waterline; and $K=1$ in general; for particular loading conditions and hull forms, calculation of $K$ according to the following formula may be necessary: $K=13 \mathrm{GM} / \mathrm{B}$, where $K \geq 1$ and GM is the metacentric height $(\mathrm{m})$.

$$
A=\left(0.7-\frac{L_{0}}{1200}+5 \frac{z}{L_{0}}\right) \cdot\left(\frac{0.6}{C_{\mathrm{B}}}\right),
$$

where $V$ is the service speed (knots) and $a_{x}, a_{y}$, and $a_{z}$ are the maximum dimensionless accelerations (i.e., relative to the acceleration of gravity) in the respective directions. They are considered as acting separately for calculation purposes, and $a_{z}$ does not include the component of the static weight; $a_{y}$ includes the component of the static weight in the transverse direction due to rolling, and $a_{x}$ includes the component of the static weight in the longitudinal direction due to pitching. The obtained accelerations are applicable only to ships at or near their service speed, not while at anchor or near stationary in exposed locations.

4.1.4. Determination of Design Pressure and Load Cases. To evaluate the structural integrity of the LNG fuel tank, a calculation of load cases specified in the IGC Code was used. A total of eight load cases considering the pressure due to self-weight of the structure, thermal load due to the temperature gradient in the fuel tank, vapor pressure in the inner tank, heeling condition $\left(30^{\circ}\right)$, liquid hydrostatic pressure, and dynamic pressure due to accelerations are summarized in Table 5. The angle of the heeling situation was assumed to be $30^{\circ}$. The load of collision condition was 
TABLE 3: Specification of the target ship with the type-B independent tank.

\begin{tabular}{lcccccccc}
\hline$L(\mathrm{~m})$ & $C_{\mathrm{B}}$ & $B(\mathrm{~m})$ & $x(\mathrm{~m})$ & $y(\mathrm{~m})$ & $z(\mathrm{~m})$ & $V(\mathrm{knot})$ & $K$ & $\rho\left(\mathrm{kg} / \mathrm{m}^{3}\right)$ \\
\hline 366 & 0.65 & 48 & -101 & 0 & 0.5 & 23 & 1 & 500 \\
\hline
\end{tabular}

TABLE 4: Calculated results of accelerations.

\begin{tabular}{lcr}
\hline Vertical acceleration $\left(a_{z}\right)$ & Transverse acceleration $\left(a_{y}\right)$ & Longitudinal acceleration $\left(a_{x}\right)$ \\
\hline $0.491 \mathrm{G}$ & $0.433 \mathrm{G}$ & $0.106 \mathrm{G}$ \\
\hline
\end{tabular}

TABLE 5: Load cases of the structural analysis.

\begin{tabular}{|c|c|c|c|c|c|c|c|c|c|c|}
\hline \multirow{3}{*}{\multicolumn{3}{|c|}{ Loads }} & \multicolumn{8}{|c|}{ Load cases } \\
\hline & & & \multicolumn{3}{|c|}{$\begin{array}{l}\text { Normal operating } \\
\text { condition }\end{array}$} & \multicolumn{3}{|c|}{$30^{\circ}$ heeled condition } & \multicolumn{2}{|c|}{ Collision } \\
\hline & & & $\begin{array}{l}\text { Acc. } \\
\text { verti. }\end{array}$ & $\begin{array}{l}\text { Acc. } \\
\text { trans. }\end{array}$ & $\begin{array}{l}\text { Acc. } \\
\text { longi. }\end{array}$ & $\begin{array}{c}\text { Acc. } \\
\text { verti_heel }\end{array}$ & $\begin{array}{c}\text { Acc. } \\
\text { trans_heel }\end{array}$ & $\begin{array}{c}\text { Acc. } \\
\text { longi_heel }\end{array}$ & $\begin{array}{l}\text { Col. } \\
\text { fore }\end{array}$ & $\begin{array}{l}\text { Col. } \\
\text { rear }\end{array}$ \\
\hline \multirow{4}{*}{\multicolumn{3}{|c|}{$\begin{array}{l}\text { LNG temp. }\left(-163^{\circ} \mathrm{C}\right) \\
\text { Self-weight (gravity } 1 . \\
\text { Vapor pressure " } P_{0} \text { " } \\
\text { Heeling }\left(30^{\circ}\right)\end{array}$}} & $\sqrt{ }$ & $\sqrt{ }$ & $\sqrt{ }$ & $\sqrt{ }$ & $\sqrt{ }$ & $\sqrt{ }$ & $\sqrt{ }$ & $\sqrt{ }$ \\
\hline & & & $\sqrt{ }$ & $\sqrt{ }$ & $\sqrt{ }$ & $\sqrt{ }$ & $\sqrt{ }$ & $\sqrt{ }$ & $\sqrt{ }$ & $\sqrt{ }$ \\
\hline & & & $\sqrt{ }$ & $\sqrt{ }$ & $\sqrt{ }$ & $\sqrt{ }$ & $\sqrt{ }$ & $\sqrt{ }$ & $\sqrt{ }$ & $\sqrt{ }$ \\
\hline & & & - & - & - & $\sqrt{ }$ & $\sqrt{ }$ & $\sqrt{ }$ & - & - \\
\hline \multirow{6}{*}{$\begin{array}{l}\text { Internal liquid } \\
\text { pressure " } P_{\mathrm{gd}} \text { " }\end{array}$} & \multicolumn{2}{|c|}{ Liquid static pressure " $P_{s}$ " } & $\sqrt{ }$ & $\sqrt{ }$ & $\sqrt{ }$ & $\sqrt{ }$ & $\sqrt{ }$ & $\sqrt{ }$ & $\sqrt{ }$ & $\sqrt{ }$ \\
\hline & & $\begin{array}{l}\text { Acc. } \\
\text { verti. }\end{array}$ & $\sqrt{ }$ & - & - & $\sqrt{ }$ & - & - & - & - \\
\hline & & $\begin{array}{l}\text { Acc. } \\
\text { trans. }\end{array}$ & - & $\sqrt{ }$ & - & - & $\sqrt{ }$ & - & - & - \\
\hline & $\begin{array}{l}\text { Dynamic } \\
\text { pressure " } P_{d} \text { " }\end{array}$ & $\begin{array}{l}\text { Acc. } \\
\text { longi. }\end{array}$ & - & - & $\sqrt{ }$ & - & - & $\sqrt{ }$ & - & - \\
\hline & & $\begin{array}{l}+\mathrm{X} \\
0.5 \mathrm{G}\end{array}$ & - & - & - & - & - & - & $\sqrt{ }$ & - \\
\hline & & $\begin{array}{l}-\mathrm{X} \\
0.25 \mathrm{G}\end{array}$ & - & - & - & - & - & - & - & $\sqrt{ }$ \\
\hline
\end{tabular}

TABLE 6: Results of the loading calculation.

\begin{tabular}{|c|c|c|c|}
\hline Load cases & Vapor pressure $(\mathrm{MPa})$ & Internal pressure $(\mathrm{MPa})$ & Total pressure for FEA $(\mathrm{MPa})$ \\
\hline Acc. verti. & & 0.14785 & 0.21785 \\
\hline Acc. trans. & & 0.13093 & 0.20093 \\
\hline Acc. longi. & & 0.12716 & 0.19716 \\
\hline Acc. verti_heel & & 0.09362 & 0.16362 \\
\hline Acc. trans_heel & 0.07 & 0.07036 & 0.14036 \\
\hline Acc. longi_heel & & 0.06358 & 0.13358 \\
\hline Col. fore & & 0.18030 & 0.25030 \\
\hline Col. rear & & 0.14505 & 0.21505 \\
\hline
\end{tabular}

determined based on the weight acting on the tank corresponding to one-half of the weight of the tank in the forward direction and one-quarter of the weight of the tank in the aft direction. Consequently, the final results of the loading calculation on the eight load cases were summarized (Table 6 ), and the calculated total pressure $\left(P_{\text {total }}=P_{0}+P_{\mathrm{gd}}\right)$ was applied to the structural analysis.

4.2. Strength Criteria of Allowable Stress. To verify the results of the structural analysis for the type-B independent tank primarily constructed of plane surfaces, the strength criterion of allowable stress was used (10), which is given in the
IGC Code. Accordingly, the allowable stresses for austenitic steels constituting the tank were derived, as follows:

$$
\begin{aligned}
& \frac{R_{\mathrm{m}}}{2.5} \leq \sigma_{\mathrm{a}}, \\
& \frac{R_{\mathrm{e}}}{1.2} \leq \sigma_{\mathrm{a}},
\end{aligned}
$$

where $\sigma_{\mathrm{a}}$ is the allowable equivalent stresses, $R_{\mathrm{m}}$ is the minimum tensile strength at room temperature $\left(\mathrm{N} / \mathrm{mm}^{2}\right)$, and $R_{\mathrm{e}}$ is the minimum yield stress at room temperature $\left(\mathrm{N} / \mathrm{mm}^{2}\right)$ as defined in the IGC Code. For SUS304L constituting the tank and support structure, $R_{\mathrm{m}}$ and $R_{\mathrm{e}}$ are 
TABLe 7: Structural analysis results according to each load case.

\begin{tabular}{|c|c|c|c|c|c|}
\hline \multirow{2}{*}{$\begin{array}{l}\text { Component } \\
\text { Material }\end{array}$} & & \multicolumn{4}{|c|}{ Max. von Mises stress $(\mathrm{MPa})$} \\
\hline & & Fuel tank structure & $\begin{array}{l}\text { Antirolling and pitching } \\
\text { SUS304L }\end{array}$ & Support structure & $\begin{array}{c}\text { Hard wood block } \\
\text { Wood }\end{array}$ \\
\hline \multirow{8}{*}{ Load cases } & Acc. verti. & 223 & 106 & 146 & 25 \\
\hline & Acc. trans. & 203 & 97 & 133 & 23 \\
\hline & Acc. longi. & 199 & 95 & 130 & 23 \\
\hline & Acc. verti_heel & 160 & 76 & 104 & 17 \\
\hline & Acc. trans_heel & 133 & 63 & 87 & 15 \\
\hline & Acc. longi_heel & 125 & 59 & 81 & 14 \\
\hline & Col. fore & 262 & 125 & 171 & 29 \\
\hline & Col. rear & 221 & 105 & 145 & 25 \\
\hline \multicolumn{2}{|c|}{ Allowable stress } & & 225 & & 125 \\
\hline
\end{tabular}

$570 \mathrm{MPa}$ and $270 \mathrm{MPa}$, respectively. Accordingly, using the value of $R_{\mathrm{e}} / 1.2$, the allowable stress is $225 \mathrm{MPa}$. For the hard wood block constituting the middle part of the support structure and antirolling and pitching device, since the tank is expanded by the internal pressure acting on it, the wood block was assumed to be mostly subjected to a compressive load. The compressive strength of the wood block used was $125 \mathrm{MPa}$. Accordingly, the allowable stress was set as $125 \mathrm{MPa}$ according to the minimum compressive strength of the model of the hard wood block used in the LNG fuel tank. The PUF constituting the insulation was excluded during the strength assessment in the structural analysis because it is not a structural member subjected to stress.

4.3. Structural Analysis Results. By performing the structural analysis, the von Mises equivalent stress was derived for each load case. A summary of the analytical results is presented in Table 7. As the allowable stress calculated using the rule for SUS304L is $225 \mathrm{MPa}$, the result in the load case of fore collision is unsatisfactory. However, except for this case, all the results satisfied the allowable stress. Since the collision case belongs to the accidental limit state, it is considered that a little flexible design is needed for this result. The FEA results for the equivalent stress distribution in the tank structure are shown in Figure 9. This result was for the representative severe load case of fore collision among the entire load cases. The maximum stress value was $262 \mathrm{MPa}$ and occurred at the specific joint section of the primary barrier, which was due to the shape where stress concentration can easily occur. Since the maximum stress level was observed at the typical structural joint part due to its geometrical characteristics, the typical structural joint was defined as the crucial joint and horizontal and vertical stiffeners as shown in Figure 10.

The crucial joint part and the horizontal and vertical stiffeners subjected to a stress concentration are shown in Figure 11, and a detailed comparison of the equivalent stress in terms of these parts for each load case is shown in Figure 12. At the crucial joint part, lower stress concentration was observed, while at the part reinforced in only one direction horizontally or vertically, higher stress concentration was observed. Accordingly, structural

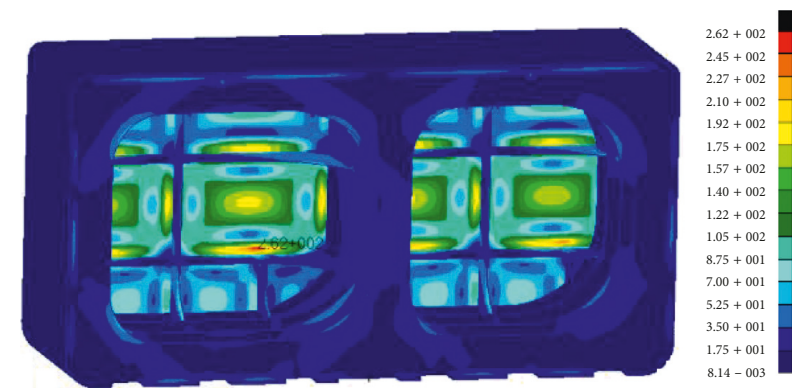

FIGURE 9: Structural analysis results on equivalent stress distribution of the LNG fuel tank.

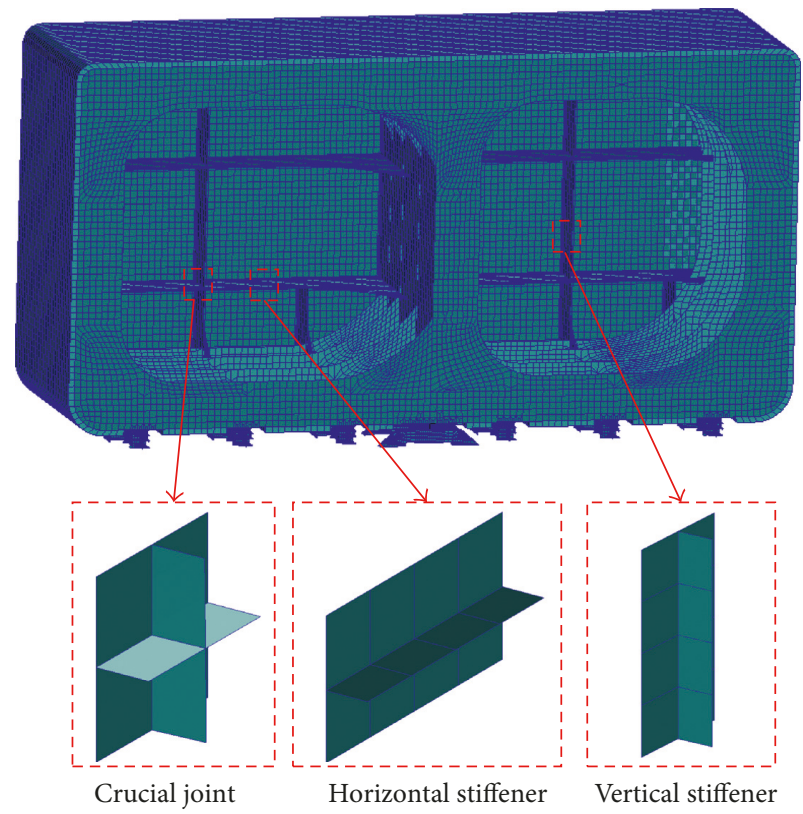

Figure 10: Typical structural joint of the LNG fuel tank.

strengthening by increasing the thickness of the joint part or using more stiffeners is required. Furthermore, it can be observed that lower stress occurred in the vertical stiffeners of the same size than in the horizontal stiffeners for all applied loads in all cases. While both parts are in a dangerous range, the vertical stiffener should be reinforced first. The stress at the part reinforced in only one 


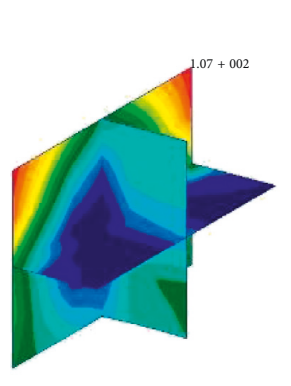

(a)

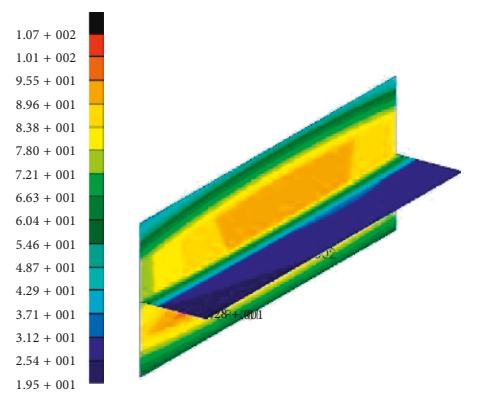

(b)

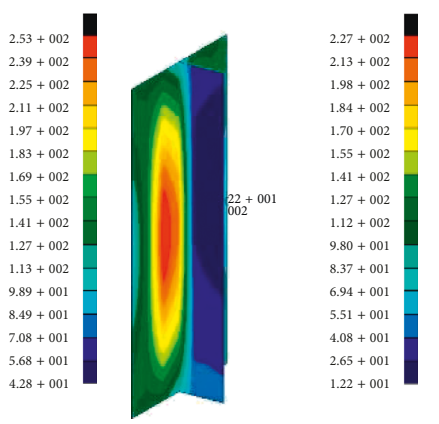

(c)

FiguRE 11: Structural analysis results on equivalent stress distribution of the (a) crucial joint, (b) horizontal stiffener, and (c) vertical stiffener.

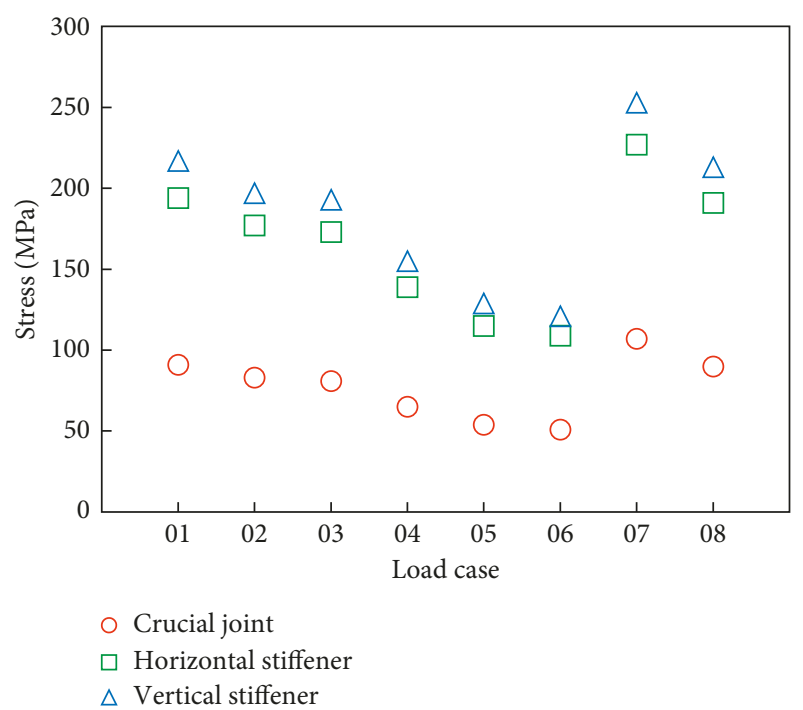

FIGURE 12: Comparison of equivalent stress at the typical structural joint for each load case.

direction was more than twice that of the joint part. It is possible that stresses resulting from the spacing between the stiffeners can be estimated and applied to the design. In addition, the reason why the stress result of the longitudinal acceleration load case of heeling is the smallest is that the dynamic pressure due to the influence of the smallest longitudinal acceleration is applied. However, as the results of the load case of vertical acceleration are higher than those of the load case of rear collision, it can be concluded that the vertical acceleration is the more disastrous condition than the rear collision and should be considered next to fore collision. In addition, when evaluating the structural strength according to the IGC Code, the heeling condition was not considered for convenience, but the vertical acceleration and forward collision were considered as top priority.

To investigate the effect of the components of pressure acting on the tank, the individual analysis was performed by applying separately each of the pressure components of internal pressure and vapor pressure, which have a large effect. The comparison of the ratios of the stress induced by

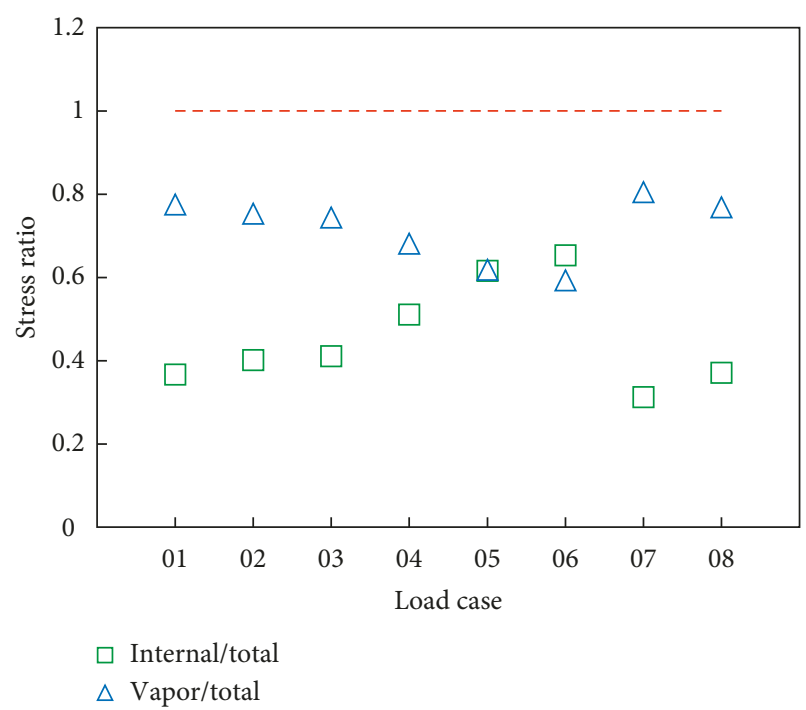

FIgURE 13: Comparison of the stress ratio for each load case.

applying the total pressure and the stress induced by applying the internal pressure for each load case is shown in Figure 13. As shown in the figure, the reversal in the graph occurred because the effect of acceleration was very small in the longitudinal acceleration load case of heeling. In addition, the average stress induced by applying the internal pressure was $71 \%$ of that induced by applying the total pressure. The average stress value induced by applying the vapor pressure was $45 \%$ of that induced by applying the total pressure. Moreover, in the load case of fore collision, the ratio of internal pressure to total pressure was $80 \%$. Accordingly, as mentioned above, the effect of internal pressure was the most significant among the various loading components in the analysis. Therefore, as it is an important factor affecting the stress results, we should focus more on the internal pressure than on other components in designing a tank.

\section{Fatigue Analysis}

5.1. Fatigue Damage Calculation and Simulation Method. The evaluation criteria and parameters for assessing the fatigue 
life of the LNG fuel tank are given in the IGC Code, ASME Sec. VIII, Div. 2, and IACS Recom. 56 [30-32]. In this study, to evaluate the fatigue life, the fatigue damage was calculated by using Miner's rule set out in the IGC Code. The estimation of the cumulative fatigue damage ratio is performed as follows.

5.1.1. Definition of Fatigue Damage. It is defined for failures that can be reliably detected by means of leakage detection as follows: the maximum allowable cumulative fatigue damage ratio $C_{\mathrm{w}}$ calculated by using (11) shall be less than or equal to 0.5 in the case of independent type-B fuel tank:

$$
\sum \frac{n_{i}}{N_{i}}+\frac{n_{\text {Loading }}}{N_{\text {loading }}} \leq C_{\mathrm{w}}
$$

where $n_{i}$ is the number of stress cycles at each stress level during the life of the tank; $N_{i}$ is the number of cycles to fracture for the respective stress level according to the Wohler (S-N) curve; $n_{\text {Loading }}$ is the number of loading and unloading cycles during the life of the tank; loading and unloading cycles include a complete pressure and thermal cycle; $N_{\text {Loading }}$ is the number of cycles to fracture for fatigue loads due to loading and unloading; and $C_{\mathrm{w}}$ is the maximum allowable fatigue damage ratio. The S-N curve used for the calculation of the number of cycles was obtained by performing a fatigue test on stainless steel in an actual cryogenic environment. It was then applied in the analysis and is shown in Figure 14.

5.1.2. Determination of Stress Range and Design Number of Design Cycle. For calculating cumulative fatigue, the load cases of vertical, transverse, and longitudinal accelerations were defined in terms of the internal pressure, including the effect of dynamic accelerations under normal operating conditions, as specified in DNV Class Note No. 31.12. For these cases, a stress range was defined as twice the difference between stress without any acceleration (A) and stress with acceleration (B) when the LNG in the tank is in $90 \%$ filling condition considering the ASME Sec. VIII, Div. 2. It is recommended that stresses should be calculated at a moderate probability of exceedance, for example, $10^{-3}$ to $10^{-5}$. Considering the probability given in IACS Recom. 56, the time history for a probability of $10^{-4}$, which is an intermediate value (Figure 15), was arbitrarily applied in FEA for each case to determine the approximate tendency $[32,33]$.

In addition, bunkering is an essential system in ships and should be considered a major factor in tank design. Accordingly, the importance and risk of bunkering have been reported [34, 35]. For calculating fatigue caused by loading and unloading, a bunkering case was defined with respect to LNG bunkering under normal operating condition. For this case, a stress range was defined as twice the difference between the stress with an empty LNG fuel tank (C) and the stress with a full tank without any acceleration (D) considering the ASME Sec. VIII, Div. 2. Using 1000 cycles is recommended, corresponding to a return period of at least

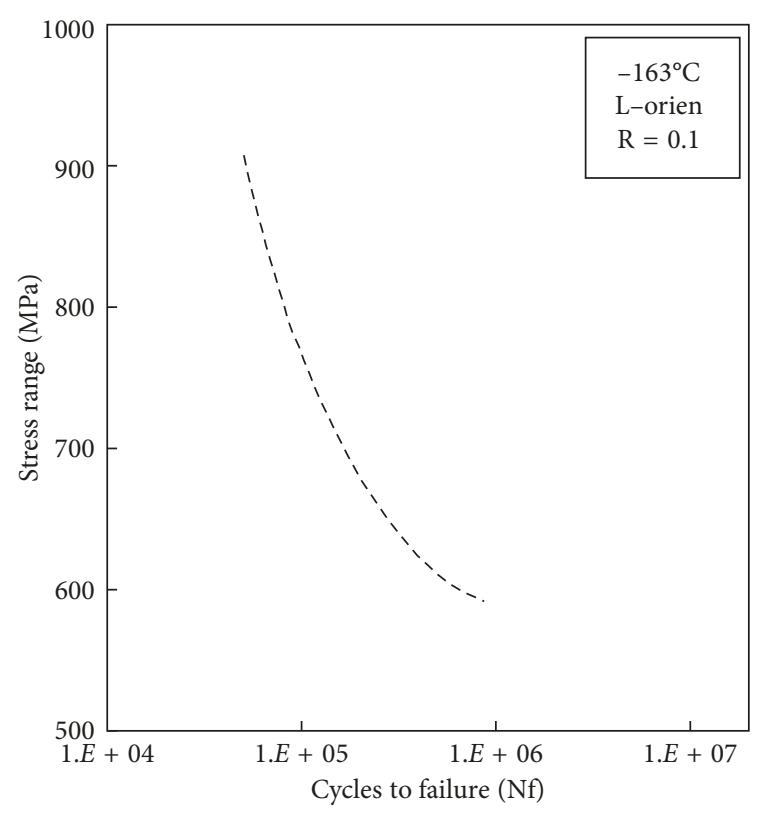

Figure 14: S-N curve for 304 stainless steel under cryogenic condition.

20 years. Therefore, the time history for a probability of $10^{-3}$ (Figure 15) was applied to the FEA for the bunkering case $[32,33]$. It reflects the relationship between the time and load induced before and after bunkering of the LNG fuel tank, and it is combined with three conditions, namely, loading (1 day), operating (5 days), and unloading (1 day). As a result, $n_{i}$ is 10,000 cycles according to the IACS Recom. 56, and $N_{i}$ is the repeat life obtained from the FE analysis. Furthermore, $n_{\text {Loading }}$ is 1000 cycles according to the IGC Code, and $N_{\text {Loading }}$ is the repeat life obtained from the FE analysis by applying the stress derived from the structural analysis for the loading conditions of internal pressure including the effect of the vertical, transverse, and longitudinal accelerations. Finally, the fatigue life of the fuel tank structure was assessed using the sum of the analysis results for the two cases mentioned above.

5.2. Fatigue Analysis Results. The fatigue analysis for the global structure of the LNG fuel tank was conducted using the results at the location of the highest stresses in the structural analysis. The analysis results of the load cases of vertical, transverse, and longitudinal accelerations with respect to the internal pressure, including the effect of dynamic accelerations under normal operating condition, are shown in Figure 16(a). The analysis results of the bunkering case with respect to LNG bunkering under normal operating condition are shown in Figure 16(b). The calculated fatigue damage factors for the entire load cases are presented in Table 8. It can be observed that the fatigue damage of the load case of vertical acceleration is more than twice that of the load cases of transverse and longitudinal accelerations. Thus, it is known that the vertical acceleration is the most critical component in terms of fatigue, as in the structural analysis. In addition, the fatigue damage of the bunkering 


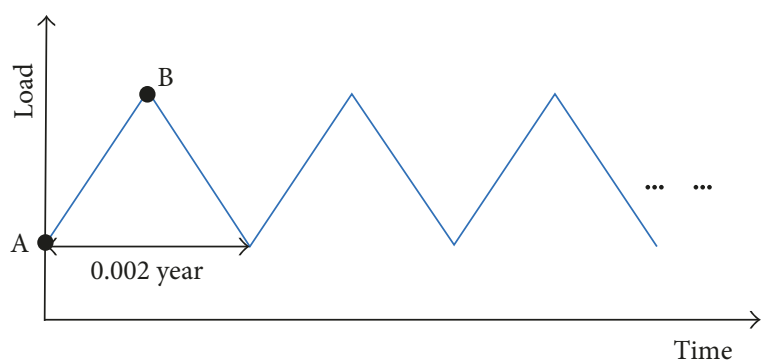

(a)

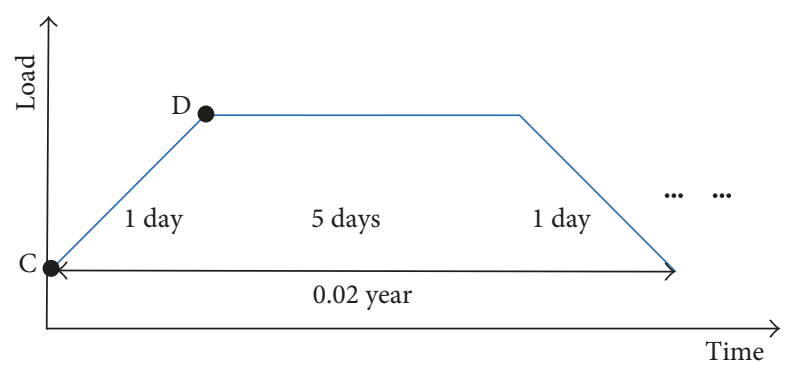

(b)

FIgURE 15: Time history: (a) load cases of vertical, transverse, and longitudinal accelerations and (b) load case of bunkering.

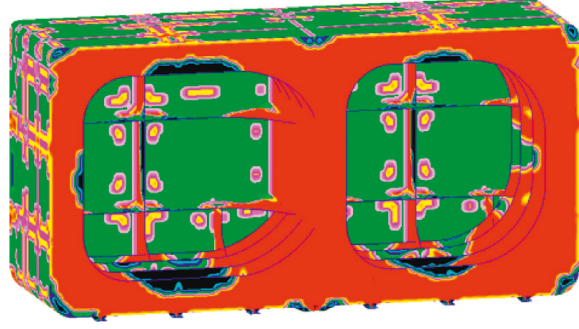

(a)

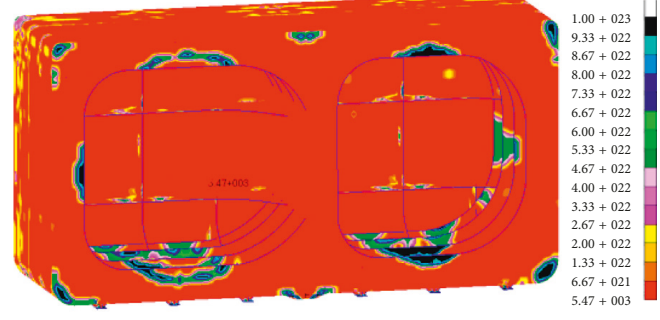

(b)

FIgURE 16: Fatigue analysis result: (a) load case of vertical acceleration and (b) load case of bunkering.

TABLE 8: Fatigue analysis results according to each load case.

\begin{tabular}{lcccc}
\hline $\begin{array}{l}\text { Load } \\
\text { cases }\end{array}$ & $\begin{array}{c}\text { Stress range } \\
(\mathrm{MPa})\end{array}$ & $N_{i}\left(N_{\text {Loading }}\right)$ & $n_{i}\left(n_{\text {Loading }}\right)$ & $\begin{array}{c}\text { Fatigue } \\
\text { damage }\end{array}$ \\
\hline Acc. verti. & 73 & 72,100 & 10,000 & 0.1387 \\
Acc. trans. & 53 & 159,000 & 10,000 & 0.0629 \\
Acc. longi. & 48 & 165,000 & 10,000 & 0.0606 \\
Bunkering & 120 & 5,470 & 1,000 & 0.1828 \\
\hline
\end{tabular}

case was approximately 3 times that of the load cases of transverse and longitudinal accelerations. In terms of fatigue, the bunkering condition, which has a relatively high repetitive stress range as compared to other components, should be considered with highest priority in the design.

The total fatigue damages on both the normal operating condition and bunkering and the fatigue damage criterion are shown in Figure 17. The maximum total fatigue damage is 0.3215 . This is less than the fatigue damage criterion suggested in the IGC Code, which is 0.5. Hence, the fuel tank is safe against fatigue fracture, and the conducted analysis offers a useful solution to the assessment of fuel tank structures under fatigue condition.

\section{Conclusion}

In this study, to design the type-B LNG fuel tank used in the real structure, the procedure for the structural integrity assessment considering the IGC Code was proposed including the thermal-structural analysis and fatigue analysis based on FEA. Accordingly, a series of finite element analysis was conducted under the various design loads and operating
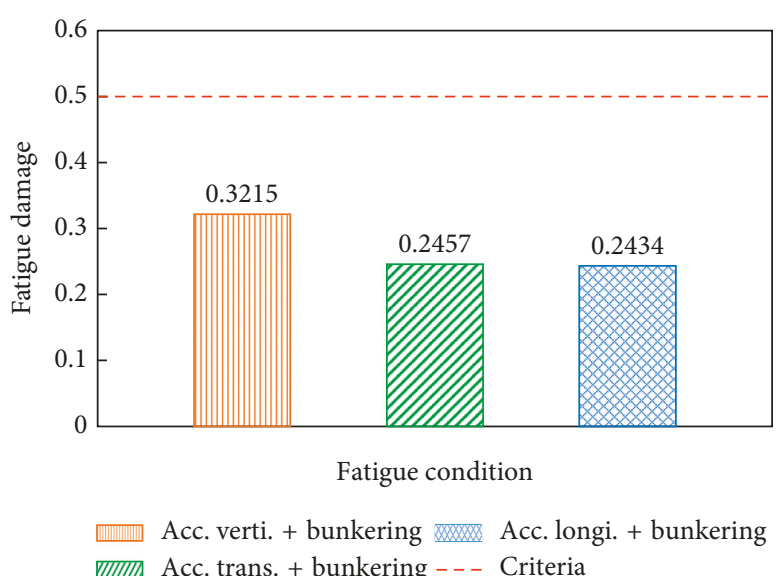

FIgure 17: Calculated total fatigue damages and fatigue damage criterion.

conditions, and fatigue life and fatigue damage were calculated using the numerical analysis results. Finally, the results were verified according to the IGC Code and several other rules. The main results are summarized as follows:

(i) Heat transfer analysis according to the filling ratio was then performed. The maximum stress level was observed at the support. Therefore, the maximum stress occurred at parts where large shrinkage was expected. In addition, it is considered that the influence on the filling ratio in the heat transfer analysis need not be deliberated because no large differences owing to the filling ratios are observed. 
(ii) At the joint part, the stress concentration was observed in the structural analysis results. It was observed that a lower stress concentration occurs in the vertical stiffeners of the same size than in the horizontal stiffeners for all applied loads in all cases. While both parts are in the risky range, the vertical stiffener should first be reinforced by increasing the thickness of the joint part or using more stiffeners.

(iii) The average stress induced by applying the internal pressure was $71 \%$ of that induced by applying the total pressure. Moreover, in the load case of fore collision, the ratio of internal pressure to total pressure was $80 \%$. Accordingly, the effect of internal pressure was the most significant among the various loading components in the analysis. Therefore, we should focus more on the internal pressure than on other components in designing a tank.

(iv) The fatigue damage of the load case of vertical acceleration was more than twice that of the load cases of transverse and longitudinal accelerations. Thus, it is considered that the vertical acceleration is the most critical component in terms of fatigue. Furthermore, the fatigue damage of the bunkering case was approximately 3 times that of the load cases of transverse and longitudinal accelerations. Therefore, the bunkering condition, which has a relatively high repetitive stress range as compared to the other components, should be considered with highest priority in the design.

\section{Conflicts of Interest}

The authors declare that they have no conflicts of interest.

\section{Acknowledgments}

This work was supported by the National Research Foundation of Korea (NRF) grant funded by the Ministry of Science and ICT (MSIT, Korea) (no. 2018R1A2B6007403) and the National Research Foundation of Korea (NRF) grant funded by the Korea government (MSIT) through GCRCSOP (no. 2011-0030013).

\section{References}

[1] T. Unseki, "Environmentally superior LNG-fueled vessels," Mitsubishi Heavy Industries Technical Review, vol. 50, no. 2, pp. 37-43, 2013.

[2] J. F. Helfre and P. A. C. Boot, Emission Reduction in the Shipping Industry: Regulations, Exposure and Solutions, Sustainalytics, Amsterdam, Netherlands, 2013.

[3] J. H. Kim and K. W. Chun, Technical Trends of LNG Fuelled Ship and Bunkering, Korea Evaluation Institute of Industrial Technology, Daegu, South Korea, 2014.

[4] H. Tamura, T. Ishida, H. Otsuka, and S. Miyazaki, "New LPG carrier adopting highly reliable cargo tank-IMO tank type B," Mitsubishi Heavy Industries Technical Review, vol. 50, no. 2, pp. 12-17, 2013.

[5] J. U. Heo, Y. J. Lee, J. R. Cho, M. K. Ha, and J. N. Lee, "Heat transfer analysis and BOG estimation of membrane-type LNG cargo during Laden voyage," Transactions of the Korean Society of Mechanical Engineers A, vol. 27, no. 3, pp. 393-400, 2003.

[6] B. Wang, Y. Chen, Y. S. Shin, and X. Wang, "Thermal analysis and strength evaluation of cargo tanks in offshore FLNGs and LNG carriers," in Proceedings of the 32nd International Conference on Ocean, Offshore and Arctic Engineering, Nantes, France, June 2013.

[7] S. Y. Hwang and J. H. Lee, "Comparative study on the thermal insulation of membrane LNG CCS by heat transfer analysis," Journal of the Computational Structural Engineering Institute of Korea, vol. 29, no. 1, pp. 53-60, 2016.

[8] B. Wang, Y. S. Shin, and X. Wang, "Structural integrity assessment of independent type 'C' LNG carriers," in Proceedings of the 33rd International Conference on Ocean, Offshore and Arctic Engineering, San Francisco, CA, USA, June 2014.

[9] Y. Q. Pei, S. Lu, and W. H. Liu, "Structural design and research of type-C independent tank on small scale LNG ship," Journal of Ship Production and Design, vol. 2, pp. 28-34, 2012.

[10] M. Watanabe, R. Takada, T. Okafuji, H. Tsujii, M. Kashiwagi, and Y. Kamitani, "Structural design and construction method for "apple-shaped liquefied natural gas cargo tank" for LNG carriers," Mitsubishi Heavy Industries Technical Review, vol. 53, no. 2, pp. 11-18, 2016.

[11] W. H. Liu, "Load analysis of C-type independent liquid cargo of LNG ship," Ship and Ocean Engineering, vol. 2, pp. 1-6, 2012.

[12] C. Alain and C. Guido, "Liquid sloshing in ship tanks: a comparative study of numerical simulation," Marine Structures, vol. 12, no. 3, pp. 183-198, 1999.

[13] M. J. Park, B. K. Choi, and Y. I. Kim, "On the efficient time domain stress analysis for the rolling chock of an independent type LNG tank targeting fatigue damage evaluation," Marine Structures, vol. 53, pp. 32-51, 2017.

[14] M. Huther, F. Benoit, and J. Poudret, "Fatigue analysis method for LNG membrane tank details," in Proceedings of the Extreme Loads Response Symposium, Arlington, VA, USA, October 1981.

[15] M. H. Kim, S. M. Lee, J. M. Lee, B. J. Noh, and W. S. Kim, "Fatigue strength assessment of MARK-III type LNG cargo containment system," Ocean Engineering, vol. 37, no. 14-15, pp. 1243-1252, 2010.

[16] K. Koyama, "CFD simulation on LNG storage tank to improve safety and reduce cost," Systems Modeling and Simulation, vol. 1, pp. 39-43, 2007.

[17] A. A. Kuriakose, "Sloshing analysis of a spherical LNG tanker," IOSR Journal of Mechanical and Civil Engineering, vol. 2, no. 5, pp. 17-22, 2014.

[18] J. H. Kim, S. K. Kim, M. H. Kim, and J. M. Lee, "Numerical model to predict deformation of corrugated austenitic stainless steel sheet under cryogenic temperatures for design of liquefied natural gas insulation system," Materials and Design, vol. 57, pp. 26-39, 2014.

[19] S. W. Yoo, C. S. Lee, W. S. Park, M. H. Kim, and J. M. Lee, "Temperature and strain rate dependent constitutive model of TRIP steels for low-temperature applications," Computational Materials Science, vol. 50, no. 7, pp. 2014-2027, 2011.

[20] MSC Software, Interface to MSC. Nastran Preference Guide Volume 1: Structural Analysis, MSC Software, Santa Ana, CA, USA, 2014.

[21] MSC Software, Interface to MSC. Nastran Preference Guide Volume 2: Thermal Analysis, MSC Software, Santa Ana, CA, USA, 2014. 
[22] MSC Software, MSC. Fatigue 2014.1 User's Guide, MSC. Patran (2014.1), MSC Software, Santa Ana, CA, USA, 2015.

[23] L. A. Halvor, Assessment of Structural Requirements Related to LNG Fuel Tanks, Ph.D. thesis, Norwegian University of Science and Technology, Trondheim, Norway, 2013.

[24] Lloyd's Register (LR), Structural Design Assessment-Primary Structure of Type B Spherical Tank LNG ships, Lloyd's Register, London, UK, 2004.

[25] P. I. Frank and P. D. David, Fundamentals of Heat and Mass Transfer, John Wiley \& Sons, Hoboken, NJ, USA, 1996.

[26] K. J. Bathe, Finite Element Procedures, Prentice-Hall, Upper Saddle River, NJ, USA, 1996.

[27] D. L. Logan, A First Course in the Finite Element Method, PWS Publishing Company, New York, NY, USA, 1993.

[28] J. H. Jeon and J. H. Heo, "Temperature distribution for a membrane type LNGC cargo tank," Journal of the Society of Naval Architects of Korea, vol. 34, no. 4, pp. 108-117, 1997.

[29] M. M. F. Hasan, A. M. Zheng, and I. A. Karimi, "Minimizing boil-off losses in liquefied natural gas transportation," Industrial and Engineering Chemistry Research, vol. 48, no. 21, pp. 9571-9580, 2009.

[30] Maritime Safety Committee (MSC), Amendments to the International Code for the Construction and Equipment of Ships Carrying Liquefied Gases in Bulk (IGC Code), Resolution MSC.370(93), International Maritime Organization, London, UK, 2014.

[31] American Society of Mechanical Engineers (ASME), An International Code 2007 ASME Boiler \& Pressure Vessel Code, ASME Sec. VIII, Div. 2, ASME, New York, NY, USA, 2007.

[32] International Association of Classification Societies (IACS), Fatigue Assessment of Ship Structures, IACS Recommendation No. 56, IACS, London, 1999.

[33] Det Norske Veritas (DNV), Strength Analysis of Liquefied Gas Carriers with Independent Type B Prismatic Tanks, Classification Notes No. 31.12, DNV, Oslo, Norway, 2013.

[34] J. Herdzik, "Consequences of using LNG as a marine fuel," Journal of KONES, vol. 20, no. 2, pp. 159-166, 2013.

[35] K. M. Jang, H. M. Ha, Y. D. Ryou, Y. S. Kim, K. D. Kim, and S. H. Hong, "Feasibility study of bunkering and worldwide current status for LNG fueled ship," in Proceedings of the KIGAS Spring Conference, Chungbuk, Korea, March 2011. 


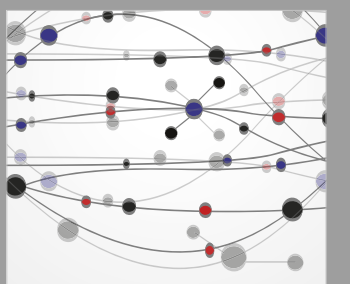

The Scientific World Journal
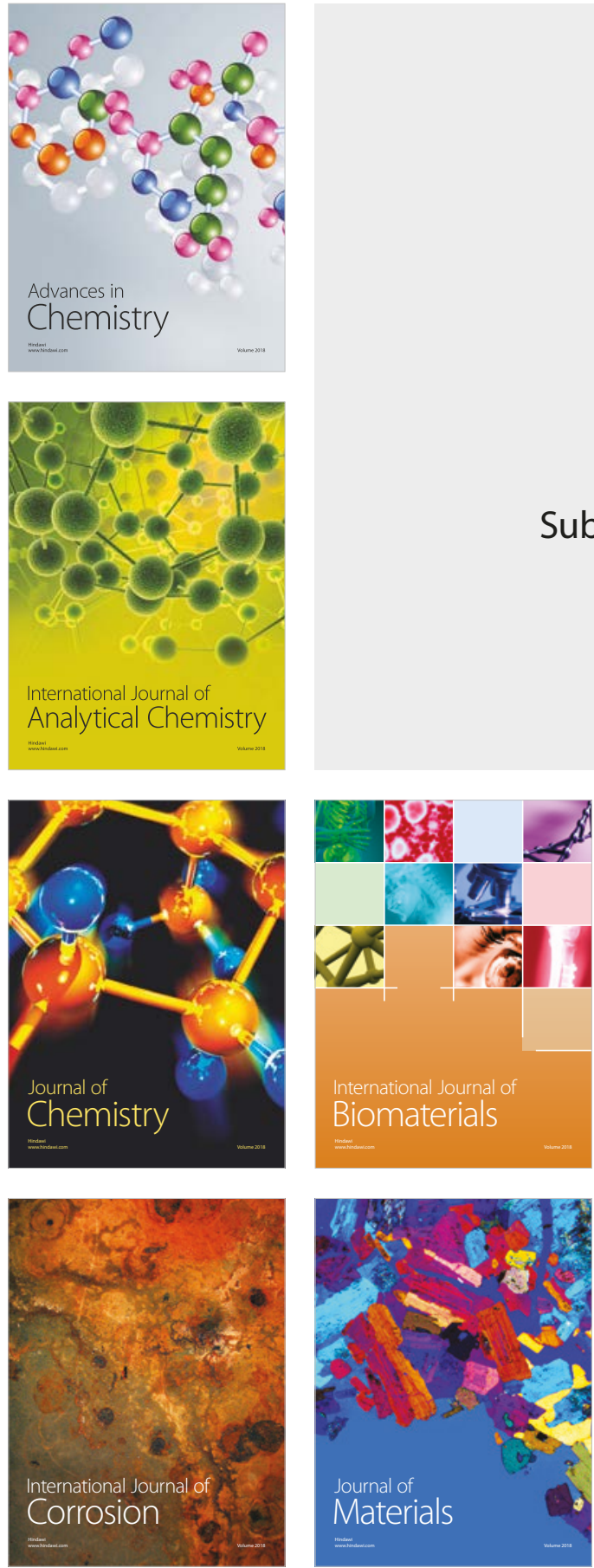

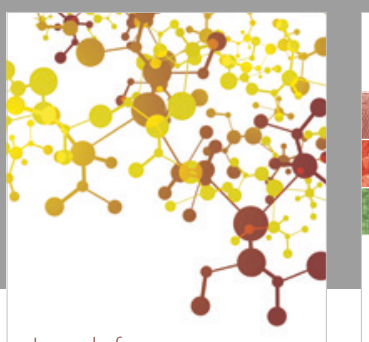

Journal of

Applied Chemistry
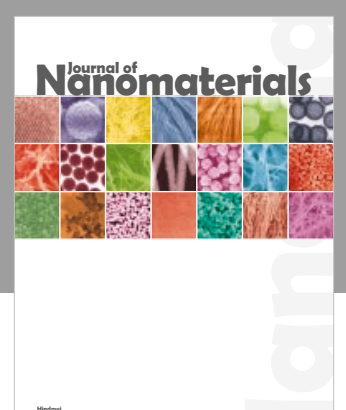

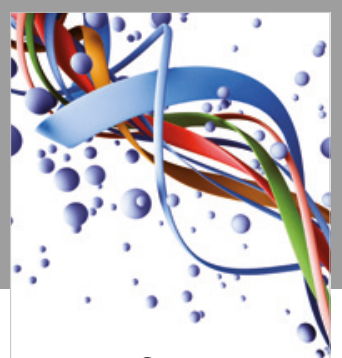

Scientifica

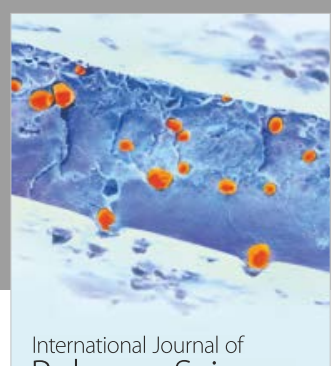

Polymer Science

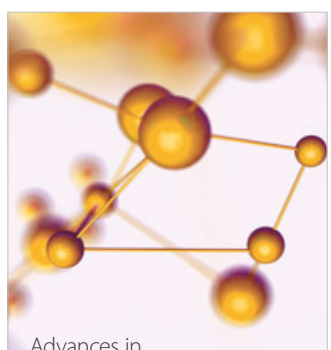

Physical Chemistry
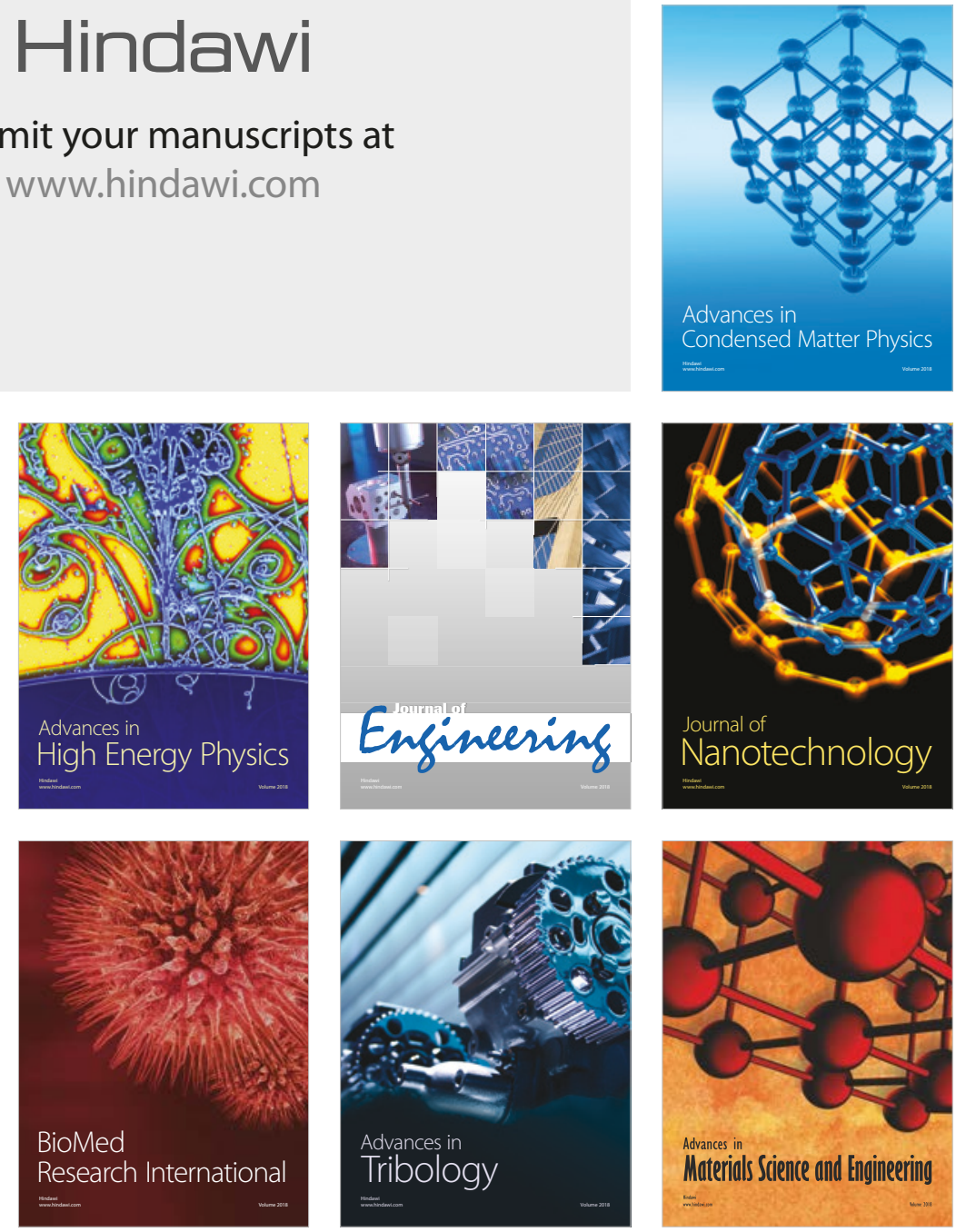